Journal of Design and Science

\title{
Future Shaped By Pasts That Could Have Been
}

Alexandra Daisy Ginsberg, Natsai Chieza, Betül Kaçar, Ytasha Womack, Justinas Vilutis

Published on: Oct 23, 2018

DOI: $10.21428 / 5 \mathrm{e} 41 \mathrm{a} 54 \mathrm{a}$

License: Creative Commons Attribution 4.0 International License (CC-BY 4.0). 
Ytasha L. Womack is an afrofuturist, writer, and film director. Known for her influential primer, Afrofuturism: The World of Black Sci-Fi and Fantasy Culture (2013), she also writes afrofuturist fiction, including Rayla 2212, a time travel and reincarnation series. She directed the afrofuturist

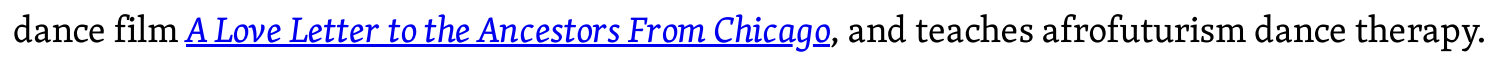
Betül Kaçar is a synthetic biologist and astrobiologist, assistant professor at the University of Arizona in molecular biology and astronomy, and an investigator at the NASA Astrobiology Institute. She uses the tools of synthetic biology in an attempt to reconstruct life's past and explore how it evolved, to examine the role of chance in evolution and to ask whether life elsewhere in the universe would resemble what we have here on Earth. Ultimately, her research aims to assess the possible environmental impacts of ancient DNA on global-scale biotic signatures. She is interested in ancient biology and function at the interface of synthetic biology, evolutionary biology, and geobiology. Kaçar describes her work as making "molecular time machines" as a way to explore common ancestors and try to rebuild lost histories. Guiding us across multiple pasts and futures, their conversation explodes possibility across time and space and explores molecular time travel through genetic and imaginative engines.

Ytasha Womack: Your work is so fascinating to me because looking at how ancient genes have evolved forces us to use our imaginations to put context around what we're looking at. I think about that a lot. In afrofuturism, we're always talking about using the imagination to create new futures. But what makes afrofuturism different from other takes on futurism is an emphasis on using imagination to also reimagine the past.

Betül Kaçar: It seems that your definition of afrofuturism might be broader than most would presume. For people hearing this word for the first time, or who might have only a superficial understanding of what it means, how do you explain it?

Ytasha: Afrofuturism is a way of looking at the future, or alternative realities, through a black cultural lens. It intersects the future with black culture, the imagination, liberation, mysticism, and technology. When I say black culture, I mean people from the African continent or people of the African diaspora. Afrofuturism also engages the divine feminine concept. It engages alternative views of looking at time, with the future, past, and present being one. It's an engine for looking at how resilience and the imagination have not just saved lives but are a lifeline in a culture's evolution. 


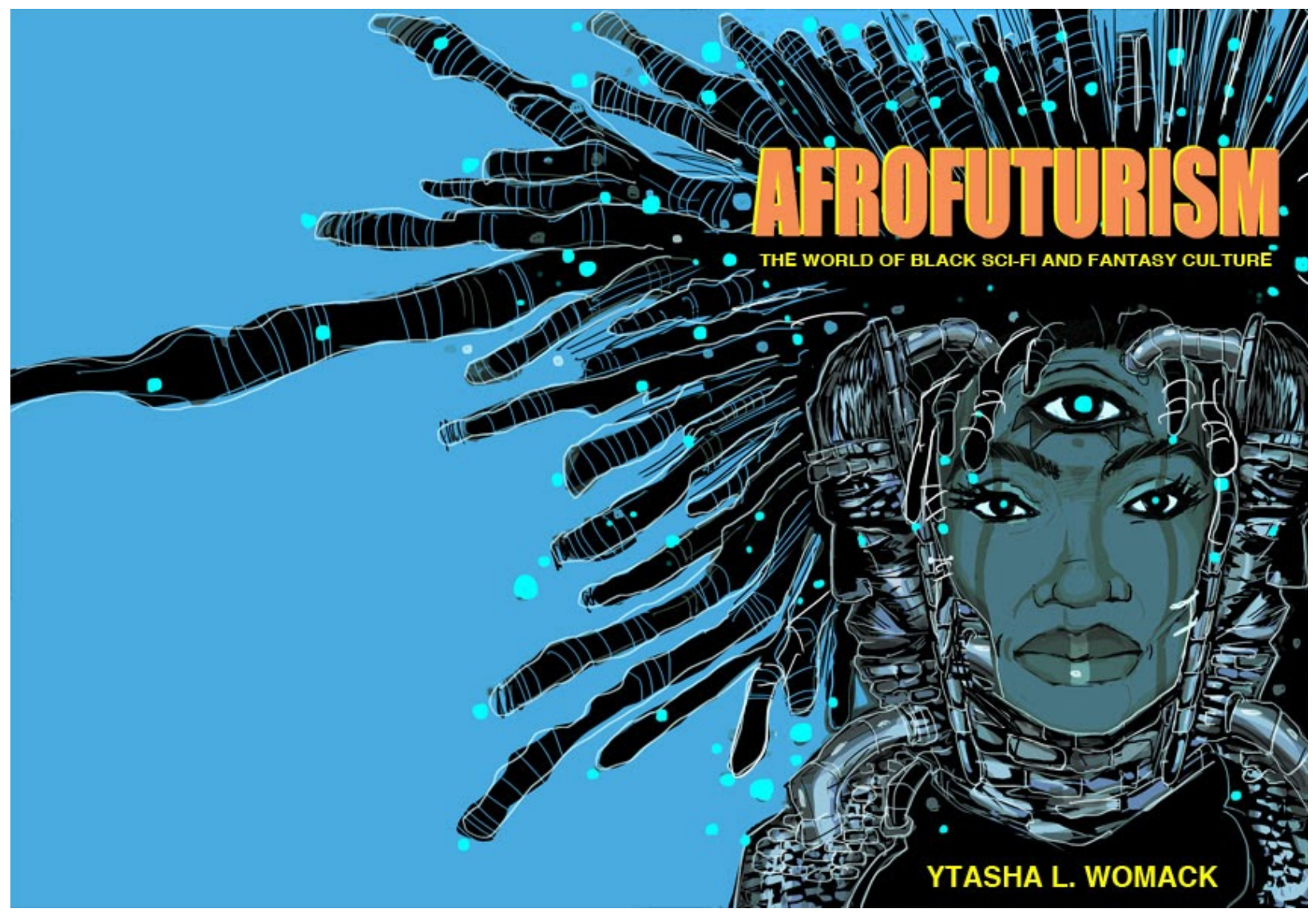

Womack's primer explores afrofuturism as "a way of looking at the future, or alternative realities, through a black cultural lens". Credit: Ytasha L. Womack.

Betül: This is fascinating. Your work looks at alternative futures that might have been, and imagines a world where anything is possible, so you are referring to a past-less state. This synthesis of past and future relates to my work. I use synthetic ancient genes to create parallel evolutionary histories, and then study the impacts of the differences that emerge, to see how they are contrary to what has actually happened, both specifically and historically. The goal is to look at whether the past traps the possibility for the genetic future. In that sense, in contrast, synthetic biology is a static phenomenon, generating systems that have only one state of time. 


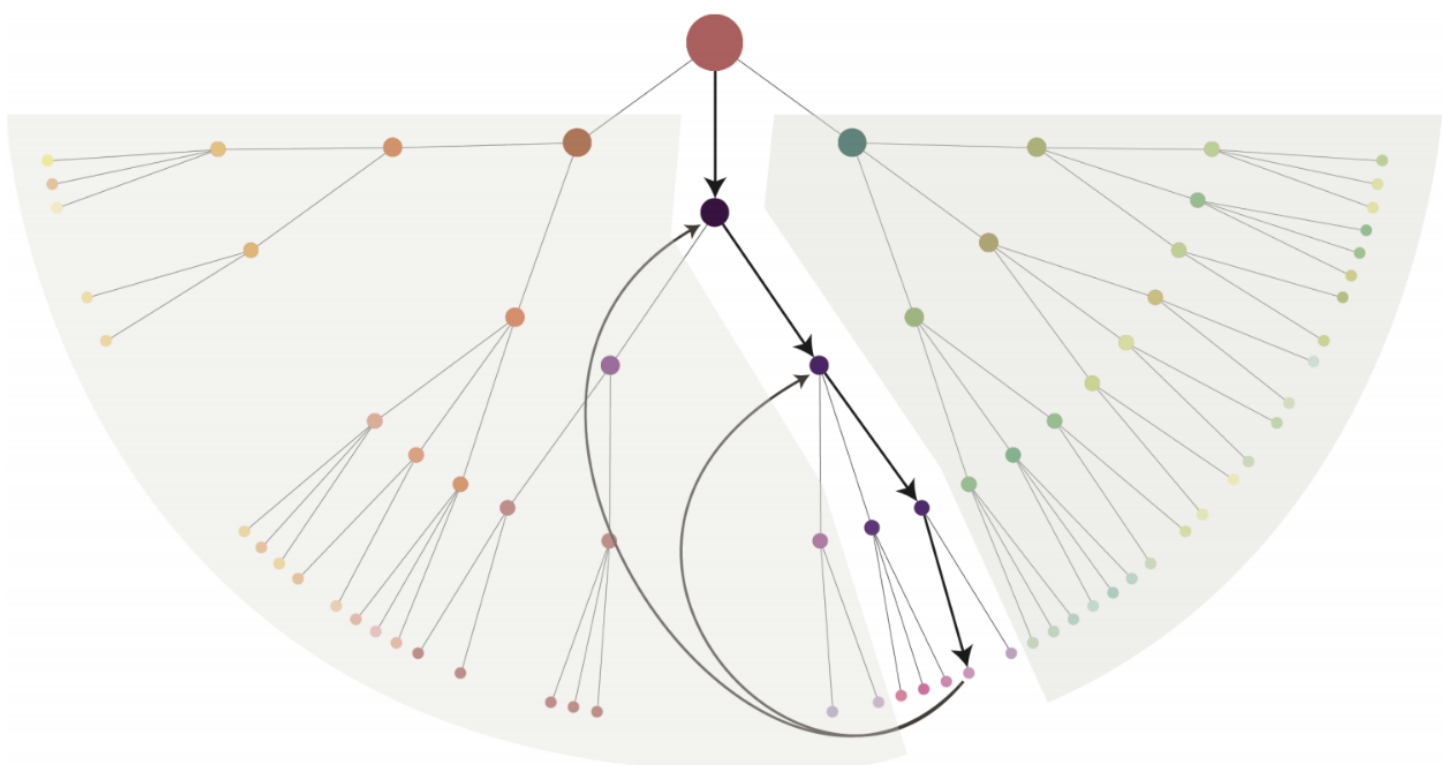

E Unibus Pluram. From one, many. A hypothetical scheme of evolutionary patterns represented by lines that sequentially bifurcate: interaction between an organism containing ancestral variants of a protein (represented by different colored circles) evolving from a common ancestor (in red) and its environment will produce a series of adaptive zones. The arrows indicate time, while the white pathway represents the evolutionary trajectory that once took place. Replaying evolution starting from successively older timepoints (shown with longer arrows) allows access to historic evolutionary states that preceded the accumulation of mutational steps, allowing the engineered organism to operate in different adaptive zones (in grey), and thus lead to other genetic possibilities (different colors). Credit: Betül Kaçar.

How would you think about my work, where I introduce artificial genes into organisms to study how those genes communicate with other cellular parts, and shape, if at all, how the organism lives? Do you see any similarities between this methodology and your view of afrofuturism?

Ytasha: Absolutely. I think one of the frustrations for people of African descent is that when we talk about the past, there's a very Eurocentric narrative and not much of an emphasis on other ancient cultures and how they evolved, or how complex they were. Sometimes we use the imagination to connect with a reality of what we would have called a past, which there aren't as many records for. Sometimes that doesn't line up with the stories we're often told in science, with respect to how cultures evolved, or how societies function. The use of imagination relates to this conversation because it helps us to recognize that what we think was the past wasn't necessarily the past. The flip side is valuing your imagination, so you don't have to be trapped by a past either.

Talking about the imagination, or visioning, from a cultural standpoint, involves a reverence for ancestors. African cultures, indigenous cultures, and a lot of ancient cultures around the world relate to their ancestors in the present. Some people have methods to communicate with ancestors to get a broader sense of what was important then, and how it relates now. That's a very real experience for 
many people, so I think there's some framing there to find other sources of what we would call "knowledge." In afrofuturism, there's real value placed on what we sometimes call the feminine aspect of humanity-intuition, emotions, feelings, nature-as being very valid information sources, equal to logic.

Betül: "Afrofuturism unchains the mind." This is a statement from your book. I had to pause a little bit when I first read it; it was really strong.

Ytasha: We are trained to think in a very linear, logical way; there's a beginning and a middle and an end. This logic tells us that time always moves forward, and we function in that world of assumptions. If, for example, you had been told that you were the child of a seamstress, and therefore you should be naturally gifted at sewing, you might think of yourself a little differently. But what if we thought of all times happening simultaneously? How would that transform our thinking? There are these default assumptions we operate under that hinder us from really connecting with ourselves.

Betül: The fact that you mentioned a world where anything is possible, to me, captures a goal of synthetic biology in some ways, because the larger assumption is that synthetic biology allows creation of biological parts inspired by nature, with no prior history. I use synthetic genes to create parallel artificial genetic histories and then study the evolutionary patterns, comparing them to what actually happened in geological or biological history. My goal is to look at how much the past dictates the present and genetic futures.

Synthetic biology is helpful in providing me access to past-less, artificial molecules, but it fundamentally misses the component of evolution. Synthetic biological parts can be considered as static states. After all, the whole point of designing a biological component from scratch is to control its behavior and program it to do whatever you command. Through this approach, synthetic biology fundamentally contradicts evolution, which is an ever-changing dynamic state shaped by the environment. 
A.

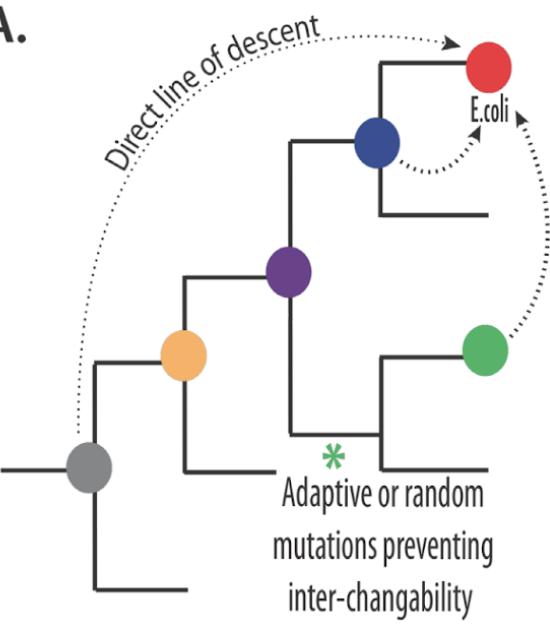

B.
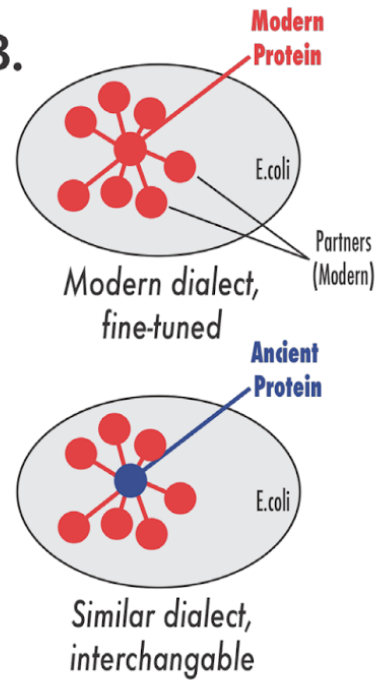

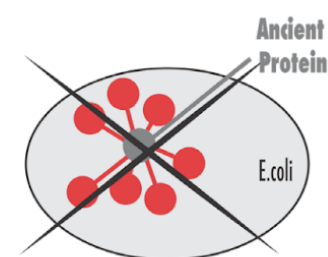

Dialect too divergent, cannot interchange

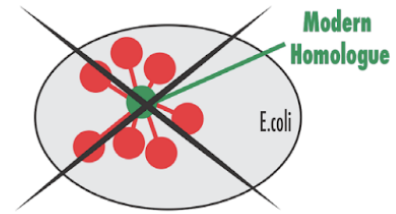

Adaptive or random mutation, cannot interchange

(A) Paleo-experimental evolution involves resurrecting an ancient gene, removing the modern form of the gene from an extant organism, and then inserting the ancestral form into the extant organism. For instance, the ancient gene from the gray node on the phylogeny can be resurrected and inserted into the $E$. coli genome (red node) at the precise chromosomal location that the extant gene was knocked out. This synthetic/engineered organism is then evolved in the laboratory. Kaçar's approach contrasts to others that only use modern genes from an organism to replace its ortholog in a different extant organism (e.g. inserting the gene from the extant organism at the green node into the E. coli)

(B) Protein interaction network containing modern and ancient hubs. Consider a particular hub protein that interacts with seven ancillary partners in $E$. coli (upper left). These interactions are fine-tuned over the course of evolution. Replacing the modern hub of

the network with a recent ancestor of $E$. coli (blue) may permit the interaction network to still function, likely in a diminished

capacity. Replacing the modern hub of the network with an ancient ancestor of E. coli (gray) may prevent the ancillary proteins from interacting with the hub altogether. Similarly, replacing the modern hub of the network with a divergent modern counterpart may prevent the interaction network from functioning despite that the same network exists in both modern organisms. Credit: adapted from Kacçr and Gaucher, 2012, Artificial Life 13, 11-18/http://dx.doi.org/10.7551/978-0-262-31050-5-ch002

Ytasha: I'm working on this story, and it's called, "A Spaceship In Brownsville," and it takes place in the 1950s. The story asks: what if you took a person from the 1950s, or the 1920s, and you brought them into today's time. How would they function or operate?

Betül: Conceptually, this is similar to what I do. I resurrect a gene from 700 million years ago and put it into today's cell.

Ytasha: I think that's so fascinating, because when I think about you creating these cells and try to imagine how they functioned millions of years ago versus how that relates to the present, I would assume that there would be progress in their evolution. I obviously don't know the subject matter like you do, but if you're looking at an ancient cell, and you're bringing it into the future, you would see this huge arc of differences, right? Our assumption would be that it would be some sort of progress, there would be some skill sets, some components or abilities of that cell, which a modern cell would have, but an ancient cell would not? But what if it was the opposite? What if that ancient cell could do all 
kinds of things that modern cells just don't have the capacity for? I think it's a super cool idea even to be thinking about - and what does that say about our idea of progress and evolution?

Betül: It's almost a molecular Rip Van Winkle. In my case, I'm resurrecting a gene that functions in the ribosome, and the fundamental operative system of the cell. I'm replacing a part of this operative system with its hundred million-year-old counterparts to monitor how the old and the new will coevolve. Because life has to find a way!

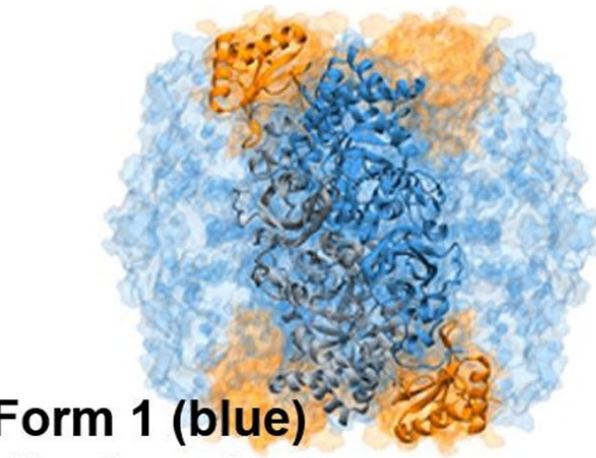

S. elongatus

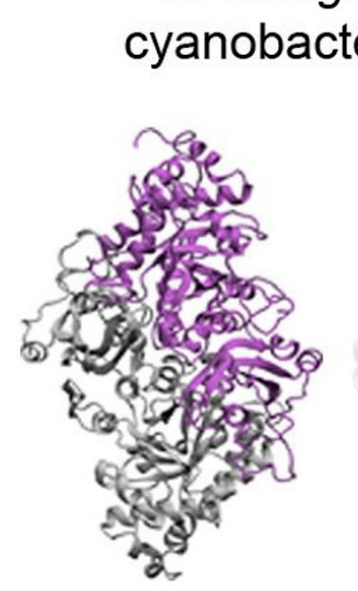

Form 2 (purple)

R. rubrum

proteobacterium

\section{m}
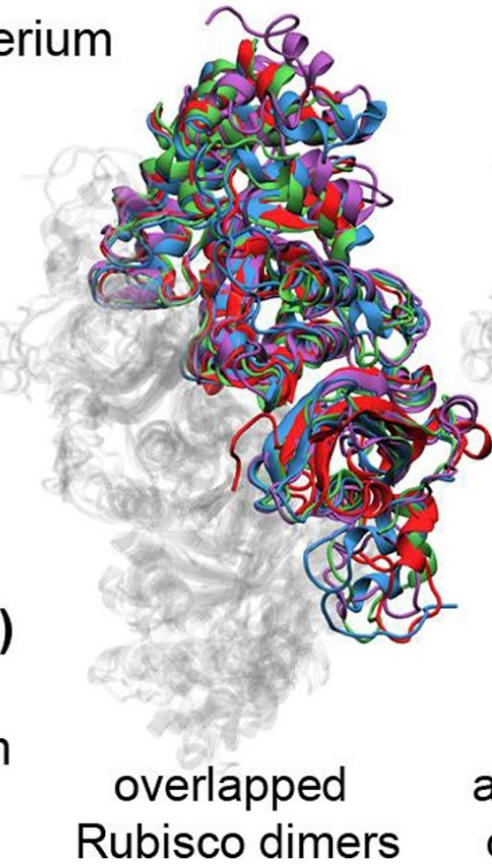

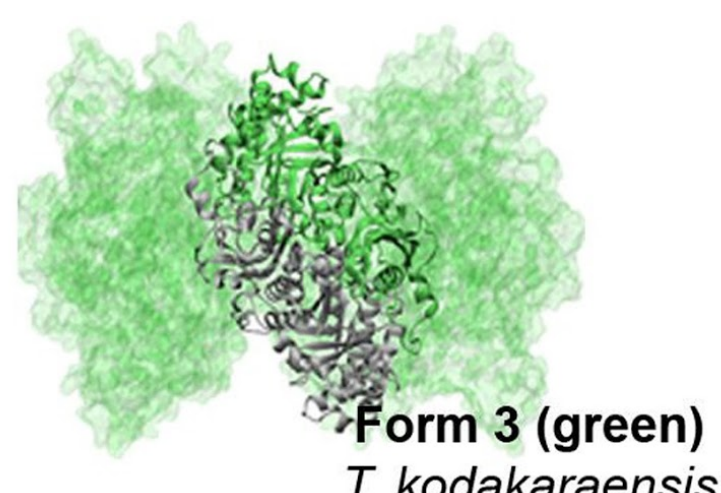

archaeon

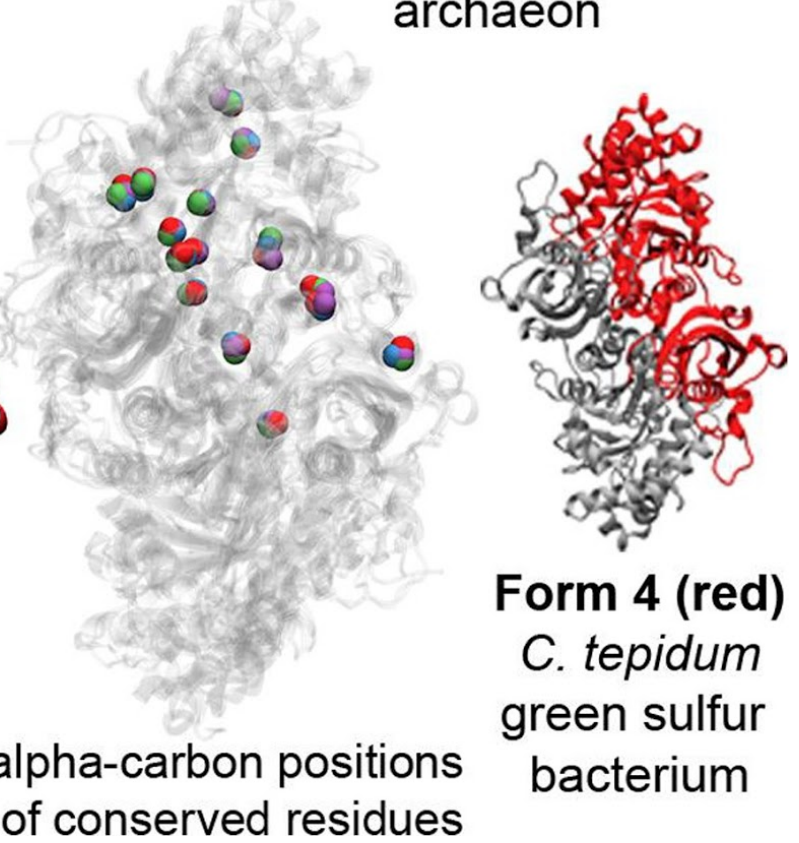

One component that Kaçar is taking between pasts and presents is the family of RuBisCo proteins, their structures shown here as they manifest today in different microorganisms. Credit: B. Kaçar, V. Hanson-Smith Z. R. Adam, \& N. Boekelheide, https://doi.org/10.1111/g gi.12243. 


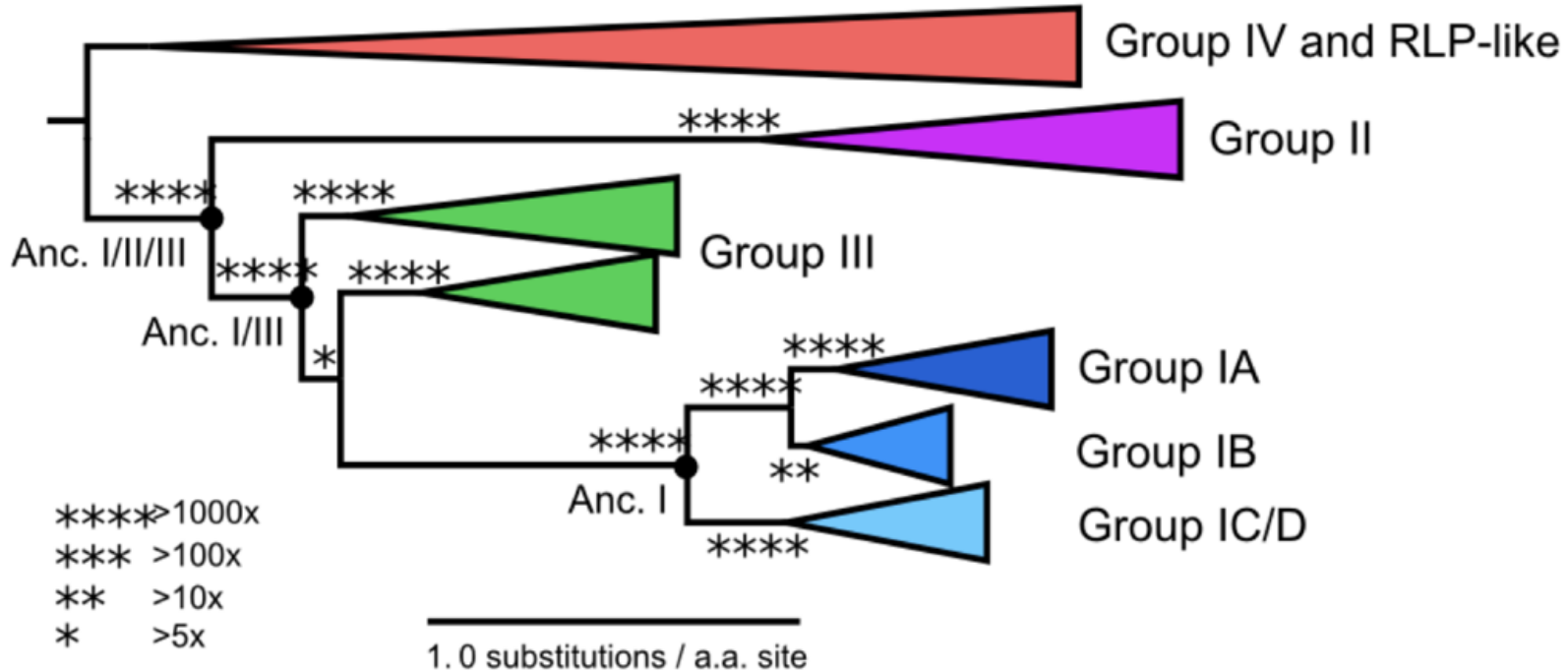

Kaçar uses computational approaches to examine the evolution of proteins, shown here is the evolutionary history of the important RuBisCO protein family. The authors collected 81 modern sequences from a broad spectrum of microbial species, reconstructed the phylogenetic tree using maximum likelihood and inferred ancestral sequences at six different time points indicated as "Anc". The branch lengths express substitutions per amino acid site. The stars on branches express their support as approximate likelihood ratios (aLR). The repository website can be found at http://www.phylobot.com/rubisco.v4/ Credit: B. Kaçar, V. Hanson-Smith Z. R. Adam, \& N. Boekelheide, https://doi.org/10.1111/gbi.12243.

Ytasha: This story I'm writing is about an opportunity to go to the future, and whether the characters choose to do so or not. This group of people, who are really into science and science fiction, and paranormal things, are in a club of sorts. It's an unlikely group of people who get together and talk about these ideas, who then have an opportunity to go to the future, which you would think everyone would take. But the future that's being articulated to them doesn't necessarily match up with their fantasies. There's also the fear of leaving the familiar and going to some future, and maybe not being able to come back.

It also goes into this whole space of identity. When you talk about being in situations where a gene doesn't remember its past, or a cell doesn't remember its past, when it's put in these hybrid situations, and then can't communicate-I just think that's fascinating.

Betül: There is a certain point in the past, when something particular happened, which changed the future evolutionary trajectory for a population altogether. The key, at least for my research, is to find that very point of bifurcation.

It's a new and terrifying realization to me that afroculture is experiencing a sort of apocalyptic trauma right now because the past, for many Africans, changed everything, and now the common cultural 
experience is a product of that trauma, and perhaps even a point in time before the enslavement existed.

Ytasha: A lot of times when people talk about black culture, they centralize the enslavement experience, or the colonial experience. It's difficult, even having conversations with people about the contributions of people from the African continent or the African diaspora and accessing the period before enslavement and colonial times began. In part, that's because so much of what people perceive as black today, is an outgrowth of that experience. However, one of the opportunities with afrofuturism, and with a lot of work that people are doing, is accepting that while there may have been certain traumas that came out of that time, exploring conditions before that period-and learning about indigenous African cultures, and their contributions-allows for even more to be brought from another time into the present.

Of course, a lot of practices that some people continue to engage with today are from ancient times. They represent a real exploration of the best of that past, and bring that forward. Look at a film like Black Panther [2018]. They have Wakanda, which in the film is a super-advanced fictional African nation; the homeland of the character Black Panther. The film offers an exploration of that idea, but I think there's a sense that still, something is lost. Well, a lot of things were lost: people were disconnected from families, you don't know your family lineage in the same way even if you take a DNA test and it can give you an origin point, so much is lost... 


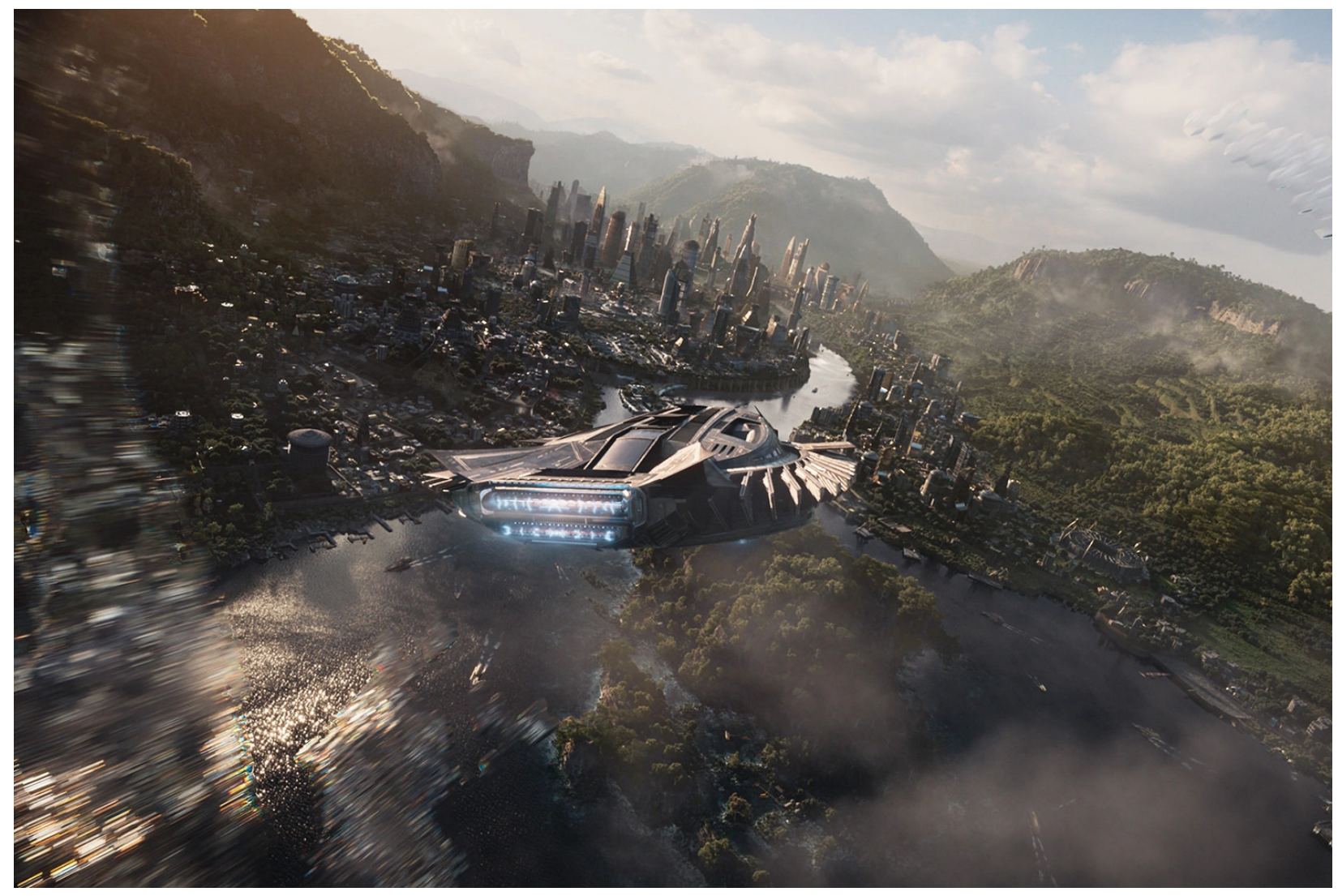

Wakanda, the fictional super-advanced African nation rendered in Marvel Studio's movie of Black Panther (2018), is hidden from view from the rest of the world as a form of self-protection. Credit: Marvel Studios.

Betül: Black Panther creates an insightful biosphere of its own, in the sense that those living in Wakanda did not experience a past like that of people in any other parts of the world. In a way there's parallel here with synthetic evolution, since there is no shared past with anything in the outside world. One important part of this synthetic history is that they did not forget their identities.

Ytasha: Correct. They held onto their identities, they did not have to deal with colonial or enslaved structures. But, although they didn't have to experience it and were able to build on the best of their past, relatively freely, they were still aware of these other things happening. So, they weren't in a complete bubble. They were aware, but they had to disguise themselves to pretend they weren't as advanced as they were, just to survive.

I think that's an element of resilience that we celebrate in afrofuturism, the unique things people may have done to survive. Part of that is using the imagination, and envisioning ourselves in different ways, or envisioning a future that helps move us out of and survive traumatic circumstances. That, I think, is 
an important avenue to explore and connect with, this resilience of the human spirit in unusual circumstances.

Betül: Even though there's no common history, somehow the two populations, or at least one population, learned from the experience of the other, and drew lessons to protect itself.

Ytasha: I'm trying to think of certain stories, where people would take on these personalities that ultimately helped protect them in these really tough circumstances, but I think there is one thing, at least in afrofuturism, that makes me think about the work that you're doing. It's the idea that although you may not know a past, or you might not be able to find tangible information, it doesn't mean you're not connected to it, and you can't somehow access information.

At least on an intuitive level, if you start getting into mysticism, whatever it is you need to know now, you can know: you're pulling from this esoteric wellspring of boundless information. But of course, in science, that's a little different. 


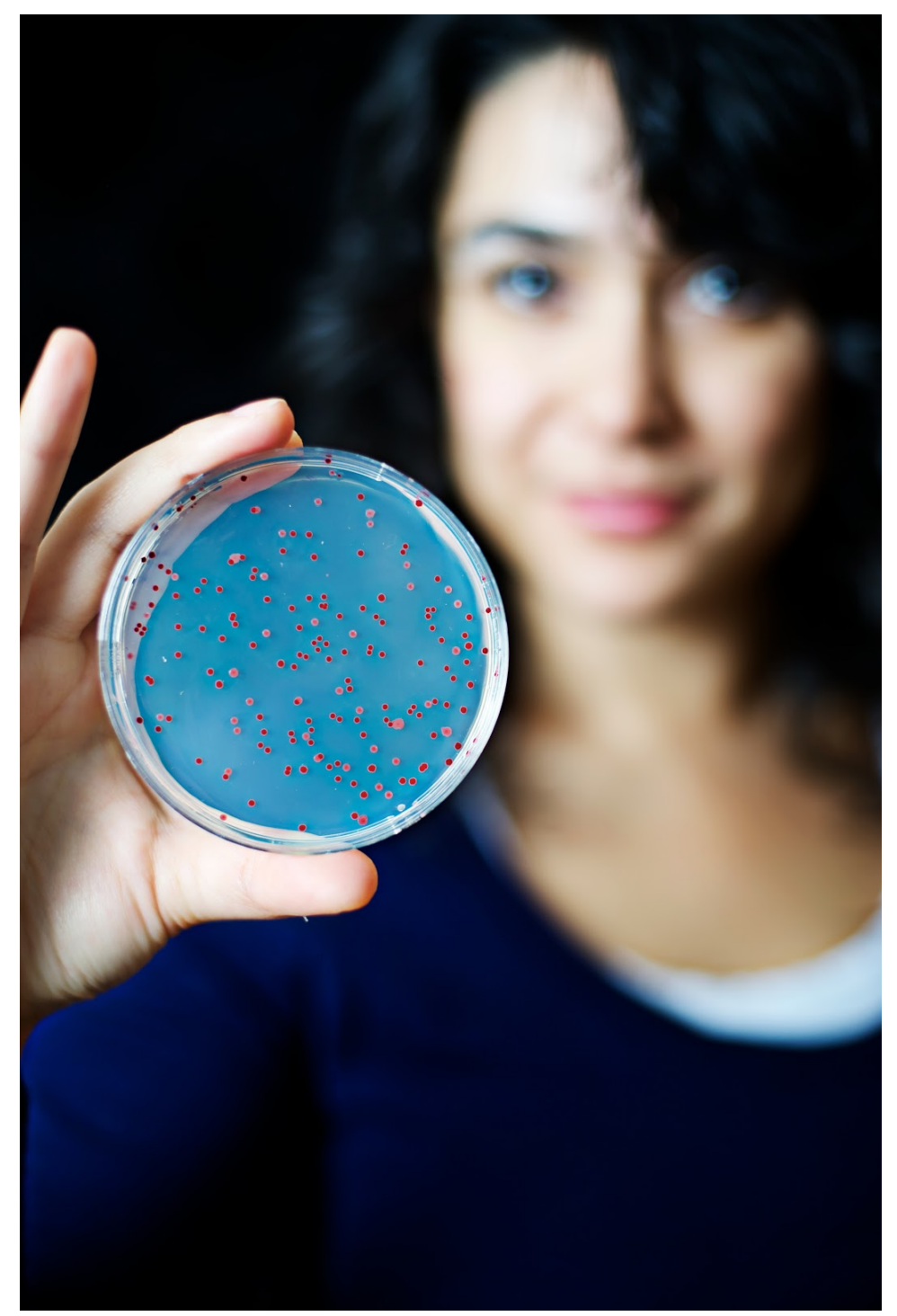

Betül Kaçar holding a plate of genetically engineered bacteria harboring ancient-modern hybrid organisms. Credit: Robin Gaucher

Betül: Especially when you're looking for alternative genetic pasts, and alternative genetic futures, because we are so constrained within the present. When I engineer a modern organism with an ancient gene, instantly I'm hoping to learn how that ancient gene lived, under what conditions, what was the environment, did it have oxygen, if so, how much oxygen did the organism have? But ultimately, I don't particularly want to evolve these organisms. Instead I want to see if the cellular communication patterns have been preserved in this way over the course of evolution, and then to infer if the trajectory that will be generated through these interactions will resemble in any way what has actually happened in the past.

I want to know whether history is repeatable, and if so, what determines this constraint. If it's not repeatable, then alternative pasts are possible, or alternative futures are possible and can be 
modified, so that we will get different futures every time.

Of course, the main interest is to understand whether we are just products of accidents or are we here for a reason in some biological sense. In anthropocentric terms, one could ask whether humans would not even be here, if life repeated itself?

If the constraints are so rigid, and every time we repeat evolution we reach the same finale over and over again, then the chances are high if we were to find life elsewhere in the universe that it will resemble what we see here. This would be due to the fact that evolutionary patterns are highly constrained on this planet. This touches upon the temporal uniqueness of life in thinking about the past, the future, the present. For me, the trick has been knowing which time point to travel to, what to resurrect, what to bring in, and what to look for.

Ytasha: What you're saying has a lot to do with multidimensionality: you're talking about alternative timelines, and that goes into this whole notion of the past, future, and present happening simultaneously, or at least the idea that there are multiple timelines, and then possibly, multiple dimensions.

To see that on a genetic level, or to speculate about that is just really, really exciting. What made you want to explore that idea?

Betül: Daniel Dennett, in his book Darwin's Dangerous Idea, talks about the time travel component of biology and how that's not possible. He was referring to the book of another biologist and philosopher, Stephen Jay Gould, who first introduced the idea of replaying the tape of life. Gould imagined life as though it was recorded on a tape, and if we rewind the tape of life and replay it, each time we would get a different story. That is because life is not dictated by any known rules, and everything is random, therefore life is highly unique in the sense that it's not going to happen over and over again.

Dennett revisited Gould's statement. In Darwin's Dangerous Idea, he states that the unfortunate thing is that no one can test this idea: we cannot possibly erase everything and re-run it. There's only one past. I thought that may be an interesting thing to try! I like the challenge of it. "Oh, you said it's not possible? Let's give it a try." That's when I thought perhaps synthetic biology and gene editing tools could be used to reconstruct alternative histories. We are not rewinding the whole tape, but perhaps a single track.

I replaced the modern component with its ancient counterpart, and at first the impact was drastic. The cells were simply not growing. Once I subjected the whole rather unhealthy system to evolution, the 
cells got healthier through acquiring largely beneficial mutations. In other words, life found a way.

Ytasha: I see why we're connected now! We're talking about this idea of multidimensionality, of history not necessarily being repeated.

One book I read some years ago, which wound up playing a significant role in my life, was called Conversations with God, by Neale Donald Walsch. In it, he's having this conversation and recording what he feels God was saying to him. It gets into the idea of the soul and how you're living your life now, but in the space of you. If you think about yourself as having lived many lifetimes, you're living all of those lifetimes now simultaneously, so your past and your future lives are all happening now, and there's some relationship. Some might have more relationships than others, but nevertheless, they're all happening at the same time. In addition to your own soul not just being in your body, you as an individual in the present could be living multiple lives in the same plane. Your soul is so multifaceted, that you can meet someone who you think is your "soulmate" but you could very well just be meeting yourself. Essentially, the idea is that your soul isn't just in your body, it can be in another body too.

I found all of this so interesting, and later when I started writing afrofuturism books, I became consumed with the story of this woman named Rayla, who I put on a planet in the future. She's a war strategist, having to find astronauts who got stuck in space and time as they tried to travel using their minds. They were attempting to go to another planet, but they couldn't because they hadn't technically been there before. Since their lineage was Earth, they wound up in previous lifetimes that they had lived on Earth. 


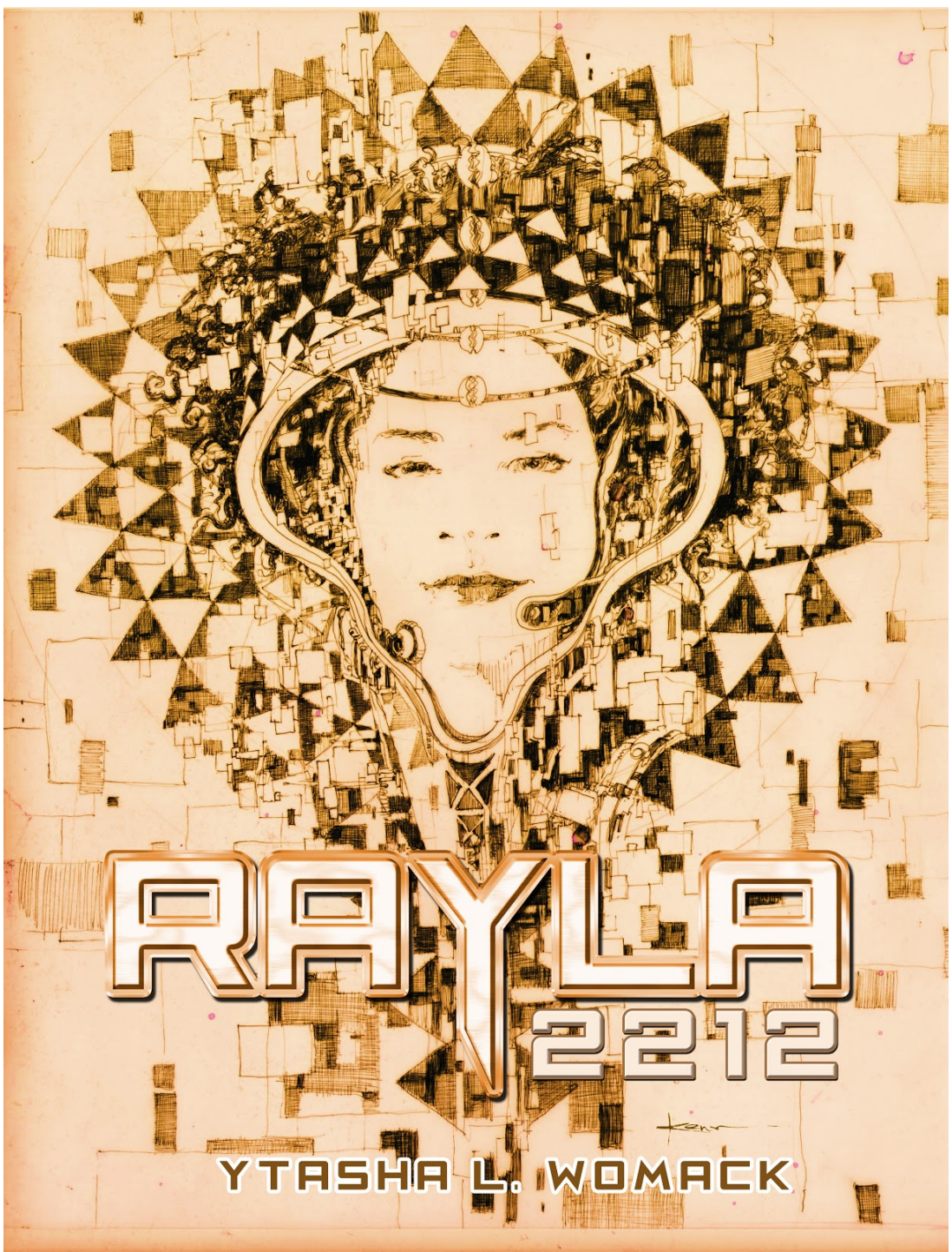

Womack's afrofuturist time travel story, Rayla 2212, follows Rayla IIImatic, a third generation citizen of Planet Hope, a former Earth colony that's claimed its independence. The story ties reincarnation, space travel, virtual worlds, and love as Rayla seeks to make her world a better place. Credit: Ytasha L. Womack.

Rayla had to go into her previous lifetimes to find them, but that whole story was really an evolution of some of the ideas that Neale Donald Walsch was talking about. If you're a person who thinks about having lived other lives, you start to try to imagine those lives, or what things you are interested in now that could be an indicator of those lives.

Instead of me trying to figure out my own life, I thought this might work better in a story context to play with that idea. It's the same thing that you're asking: Are there multiple lifetimes? Are there multiple states of existence for these different cells and genes? Are these situations repeatable? Do these genes have an actual relationship or not? Are they descendants of something, and how do they 
function? That's the heart, in my opinion, of how we're connected: it's our relationship to multiple timelines.

Betül: Exactly, and exploring whether the past traps the possibilities for a genetic future, or enables new trajectories, and if so, what happens? What are the key points in determining this difference, because it seems to be, in my case, happening all at the same time.

Ytasha: Wow. See, there we go, that's our bond. What would be interesting is, if in creating this synthetic future when you're working with the ancient cell, if the cell is somehow living a life in the synthetic future and in ancient times at the same time.

Betül: I am hoping to take my system to a level where I don't only introduce one ancient gene, but a whole cluster of ancient genes, to generate somewhat an ancient powerhouse synthetically, and then clone that inside a cell, to bring the past and the present together. The present, and past, will together build a future for this very population.

Ytasha: That is so interesting. What if part of the function of some of the cells that you're putting together was to figure out how to operate together?

Betül: That's exactly what I thought, although I didn't take that approach. Instead I replaced the cells that are responsible for cell operation, but I didn't touch the ones that are responsible for making this connection between the operator and the rest of the cell.

I guess the challenge in biology is that there are so many unknowns, in terms of what genes are actually being targeted. It's a network, an interconnected system. All the genes are equal, but some more so than others! There are some genes that are so important, that even the slightest alteration to them may lead to cellular lethality.

Ytasha: What dictates which components of the cell makes them operators? What makes them more dominant? 
Betül: That's a very good question. Some components are more connected than others: the more essential the component is, the more connected it will be, in most cases. Synthetic biology allows the design of biological parts that are free from the cellular environment. I am working on doing the opposite. I place ancient genes inside the cells to understand the interplay between the synthetic parts and the cell itself. That is our "time zero." In a way, we start building a laboratory-defined history starting from this time, in the laboratory.

Ytasha: Wow.

Betül: A snapshot of a component from the past tells you very little about the actual trajectory this component has taken.

Ytasha: This makes me think about taking a DNA test. My family and I have taken them and what's fascinating is how the haplogroups carry a narrative, a point of origin from which your story will be told. There's some idea around the group of people, or the ethnic group that you may come from, but what it can't really tell you, particularly if you're an African American person whose family came to the US through the transatlantic slave trade, is all the different cultural evolutions that occurred before that particular point. Only certain ancestors were brought to the Americas, so that gets really interesting. There's a whole story you don't know.

In my case, they started off as the Amazighs or the Berbers, but then you don't necessarily know the line of people and their specific stories. There are other dynamics that they went through, where people interacted with other ethnic groups and cultures, and you look at locations and places. You start lining up things, and everything doesn't add up, and it points to the fact that there are so many other stories. There's so much in this unknown.

Betül: We can study present all we want, and we know what's happening now, but we have no idea what happened between the past and the present; we don't have access to those histories.

That's why I wanted to evolve the system that contains this ancient gene, and my goal was to see whether I can recreate history: how this several hundred-million-year-old gene became the way it is 
today. In some ways, I rewound and replayed in order to see if the history will repeat itself, and to capture the historical steps that I cannot obtain by just looking at the past state through phylogeny [a "tree" showing evolutionary relationships among biological genes, proteins, or species]. Because what we obtain through phylogeny is the past state, this state can be thought of as a snapshot from the gene's past. Think of it as an old photo. I also have access to the current, modern photo; therefore, I know the future. Next, instead of just looking at the pictures to understand what happened in between, I animate the old photo using synthetic evolution, to see what this process will tell us about its evolved function.

In the case of my experiments, life did not repeat itself, but it generated a completely different history, it followed a different pattern. What do you think, Ytasha? Do you think life is repeatable or a completely random process, and therefore can never be repeated?

Ytasha: Okay, so let's say we take my life, and go back in time and I'm reborn, would I live the same life that I'm living now? My guess would be I might be working with some of the same concepts, but maybe not in the same way.

Betül: Are you living your life the exact same way? Are you born in the same city, do you meet the same people, go to the same school?

Ytasha: Right, if I did all those things, I think I might work with some of the same ideas, but I may have made other kinds of decisions. For example, I'm an afrofuturist writer, a filmmaker, and a dancer. I would think if I was born again, I might just be a dancer primarily, but I would also write.

Betül: If you had become an astronaut, that'd be a gain of a novel function.

Ytasha: But I'd still be working with the same concepts of the space and afrofuturism, just as an astronaut. 
Betül: What would be the thing that you do that has absolutely nothing to do with what you're doing right now?

Ytasha: If I ran a funeral home. That would have nothing to do with what I do now. I couldn't see how that would have been an outcome of anything that I did in my life.

Betül: You are the second person I met this week who would be interested in running a funeral home! Chance?

Ytasha: Synchronicity.

Betül: Running a funeral home would fit the bill and it has nothing to with science fiction, or writing, and you would not be dancing there, either, I don't think.

Ytasha: No, not as much.

Betül: Then we can conclude that your tape of life did not repeat itself.

Ytasha: Right, if that happened. I don't know how that would have happened. There would have had to be a completely different factor to push me in that direction, but that factor would have been so strong that it would have gone against my natural urges and desires.

Betül: It's interesting because I always thought that's what's missing in Stephen Jay Gould's arguments - he's the one who introduced the tape of life concept. He does not specify whether everything in this repeated life scenario will be the same as life, "take one." For instance, would a meteorite hit our planet the same day with the same intensity? For us to re-evolve as the same individual over again, does everything need to be the same: do we have to have the same lightning strikes, the same 
radiation, the same meteorite, do dinosaurs need to exist? Or it could be none of the above, and we are still here? Because then you can really conclude that life is a total mistake, that regardless of the fact that none of these things happened like they did, that it was likely, and here we are again.

Therefore, let's expect that humans will be present somewhere else in the universe, because clearly, we are destined to be. Or it is going to repeat the same way, just like you being born to your parents, going to same school and meeting the same teacher? Does this other hypothetical planet that we want to explore, go through the same same environmental factors as our planet?

Ytasha: I think that life just wants to exist. I feel like there's an essence beyond humanity where life wants to express itself in what we perceive as the three-dimensional plane that we're in, and will find a way to exist in this Earth plane regardless of what components and factors are around. Even if it's a hybrid or it doesn't resemble anything that we necessarily view as life, there's something there that's a driver to coming into existence, and to this being-ness.

Betül: Can you find similar things between this the notion of repeated life in afrofuturism?

Ytasha: I think people repeat patterns. There's this idea of traumas being repeated all the time. I've met several people, some of whom were in Hurricane Katrina, some of whom were in the West Bank, and they talked about being very traumatized, and then reading the book Afrofuturism. It helped them to get out of their trauma, or get past their PTSD, because they had been in a state where they were in perpetual motion, and they couldn't even conceive of a future.

You see patterns in nature that happen over and over again. Just the fact that we can use metaphors, and those metaphors apply to multiple situations that can be in both nature and in life itself speaks to the idea of pattern. I think the rhythm in music and sound is a pattern, and the repetition of drumbeats, or harmonies can create altered states or sense of self. That kind of repetition can really speak to someone and maybe help give them a sense of interconnectedness.

Betül: I was brought up in a Muslim family, and my family, especially my grandmother, was highly influenced by various pagan mysticisms, so I've heard a lot of interesting things. One was that life repeats itself every seven generations. I have no idea where this comes from. I suppose in the West 
this corresponds to the idea that "you are a new person every seven years." I had this strong sense that maybe I'm doing something that this person, seven generations ago, couldn't.

Ytasha: Did you feel like you were continuing that person's story?

Betül: I feel am, in some ways, doing something that they wanted to do but could not, due to reasons beyond their power. I guess the fact that I did not know about my family's past in some certainty told me something too: how poorly it was recorded! We are a family of immigrants. My family roots prior to Turkey extend to Iran and Egypt. Sadly, nothing was saved or recorded.

I tell a story that I wanted to be true, I am doing things with my life that were not offered to anyone else in my ancestry, maybe someone else in my past really wanted this opportunity as well, and I should do it for that woman too, for us.

Ytasha: I completely connect with that idea. I think it ties into DNA memory. There have been studies about DNA memory as it relates to certain kinds of traumas, but I think that there's DNA memory, too, around aspirations that people, specifically in your lineage, may have had. I mentioned before how in different indigenous African cultures, they talk about ancestors looking over you. That's the same concept that you're talking about.

Betül: Especially true for immigrants. It's a funny thing: you want to be a passenger, but also seek to be a permanent resident at the same time. I always thought of human bodies as trees: if we are indeed like trees, then what does it say about a tree if it's removed from its root, and gets planted somewhere else?

Ytasha: That's when you have to go into science or into the imagination and explore those ideas.

Betül: Whether it's biology, design, storytelling, genetics, art, history, anthropology or culture, we're both exploring creation and multidimensionality, but through different lenses and using different tactics. We're both looking at worlds where the past dictates the present and the future; where 
anything is possible. How cool is that? Let's compare notes again. Maybe we can build a world that could have been... 